\title{
Drenovac: a Neolithic settlement in the Middle Morava Valley, Serbia
}

\author{
Slaviša Perić*
}

The Late Neolithic houses excavated at Drenovac, Serbia, rank amongst the best-preserved in Europe. In particular, the preservation of collapsed second-storey floors offers unique insights into household and social organisation. The site of Slatina-Turska česma, Drenovac, is located in the Middle Morava Valley of central Serbia (Figure 1). It is a deeply stratified site, with cultural deposits up to $6.5 \mathrm{~m}$ thick, that spans two main periods of occupation (separated by a hiatus of approximately 700 years): the Early Neolithic Starčevo Culture (6100-5900 BC) and the Late Neolithic Vinča Culture (5300-4700/4500 $\mathrm{BC})$. The site was first recorded in 1966, and the first large-scale excavations undertaken between 1968 and 1971 (Vetnić 1974: 125-39; Perić 2004). In 2004, the Archaeological Institute in Belgrade conducted further excavations to improve understanding of the site's chronology, stratigraphy, formation processes and occupation dynamics (Perić 2009; Perić \& Perić 2014). Geomagnetic surveys were carried out in parallel with further excavations undertaken between 2008 and 2011 in cooperation with the RomanoGermanic Commission of the German Archaeological Institute (Perić et al. 2016) and, between 2012 and 2013, with the Viminacium Centre for New Technologies. An extensive geomagnetic survey here offers extraordinary insights into the layout and extent of the Late Neolithic settlement, and has enabled targeted excavations (Figure 1).

\section{Geomagnetic survey}

The geomagnetic survey identified 189 anomalies, thought to be debris from structures of approximately $5-7 \mathrm{~m} \times 10-12 \mathrm{~m}$ in size (Perić et al. 2016), extending over an area of 10 ha. Based on surface finds and geomagnetic anomalies in the latest Vinča phase, the Drenovac settlement as a whole must have covered around 40ha with, we estimate, approximately 700 structures. Given the longevity of the Late Neolithic settlement and its extent, an inevitable question arises as to whether all of these features were contemporaneous. In turn, this raises further questions about the number of people that inhabited the settlement at any one time, and about their social and economic organisation. Currently, it is impossible to say whether or not the entire site was occupied continuously and uniformly, and there are no data on any potential changes in its size and structure over time. Yet a possible clue to these questions may be found in the ditches within and around the settlement.

The geomagnetic survey identified a number of linear anomalies. The largest ditch, interpreted as a boundary, was identified along the western edge of the settlement, with a second, smaller ditch parallel to it. As these ditches have not been excavated, we cannot

* Institute of Archaeology, Kneza Mihaila 35/4, 11000 Belgrade, Serbia (Email: slavisa.r.peric@gmail.com) 


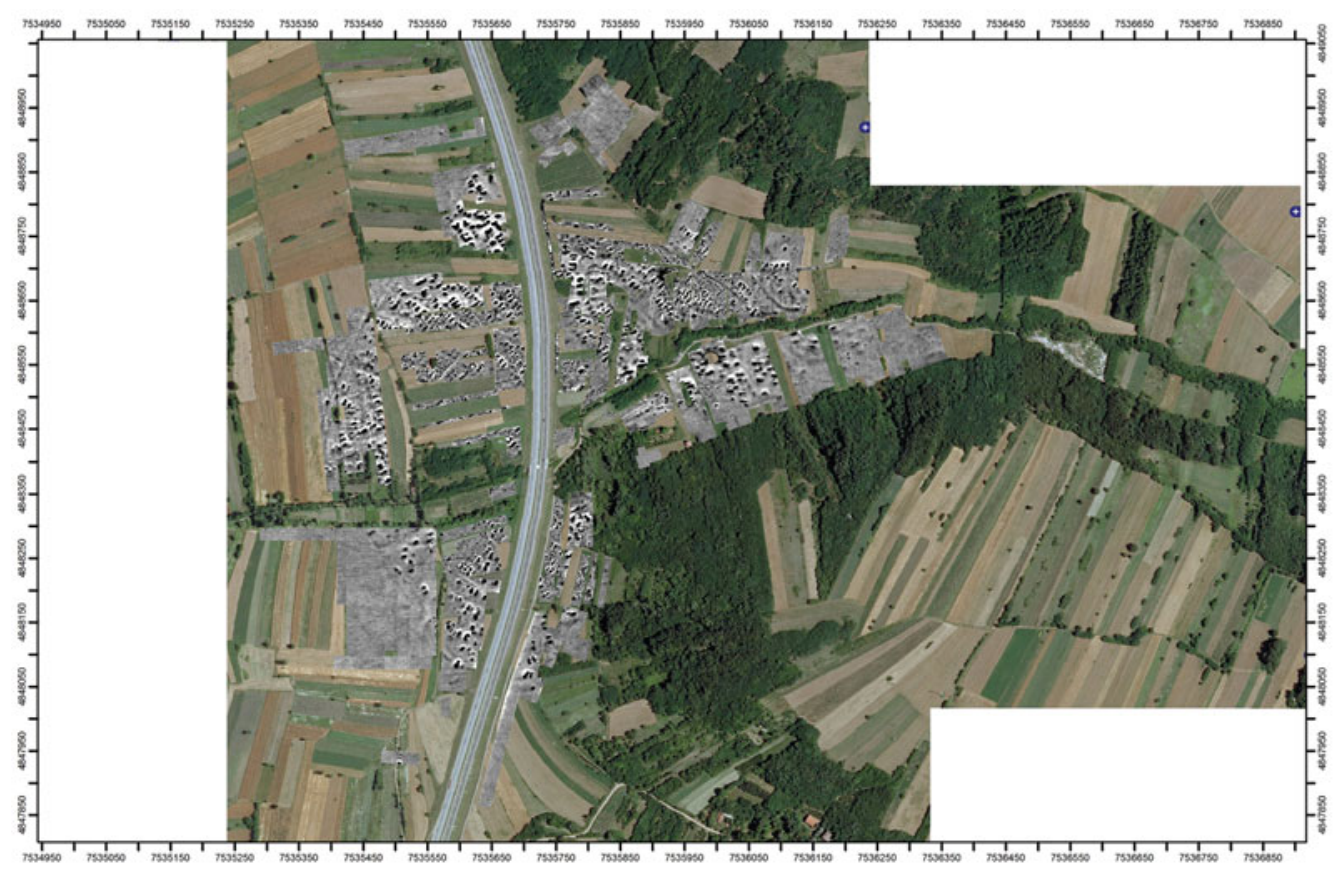

Figure 1. Drenovac-geophysical plot.

determine whether they were contemporaneous or whether they marked the settlement's changing extent in different phases. In the north-east part of the site, a small curvilinear anomaly was noted, possibly a minor ditch encircling a sub-section of the settlement (Figure 1).

Within the surveyed area, some 300 regularly shaped, rectangular anomalies were recorded, along with approximately the same number of irregular, often smaller, anomalies. The former can be confidently classified as the remains of houses, while the function of the irregular anomalies remains less certain. The most common house size is $10 \times 5 \mathrm{~m}$, followed by $12 \times 5 \mathrm{~m}$, although there are also both smaller and larger examples. The majority of structures are oriented south-west to north-east (Figures $1 \& 2$ ). In some areas of the site, the distribution of anomalies is regular, and in others, rather less so. In the regular areas, houses are set in parallel rows, with $2-6 \mathrm{~m}$ between structures and up to $10 \mathrm{~m}$ between rows, suggesting the presence of streets. In these regular areas, the spatial organisation resembles that of urban settlements, and the density of the structures would not have allowed for associated garden plots. The space enclosed by the ditch(es) (above) was allocated exclusively for residential and associated activities. Given the size of the settlement and its presumed population, arable land must have been located beyond the settlement. Some animals may have been penned next to houses, but as yet, excavation has recovered no evidence of such practices. Within the settlement, there are also zones that appear to be 'empty' (Figure 1). In some, no geomagnetic anomalies have been identified, while in others, only very weak signals have been detected. It is possible that any archaeology in these areas is more deeply buried.

(C) Antiquity Publications Ltd, 2017 


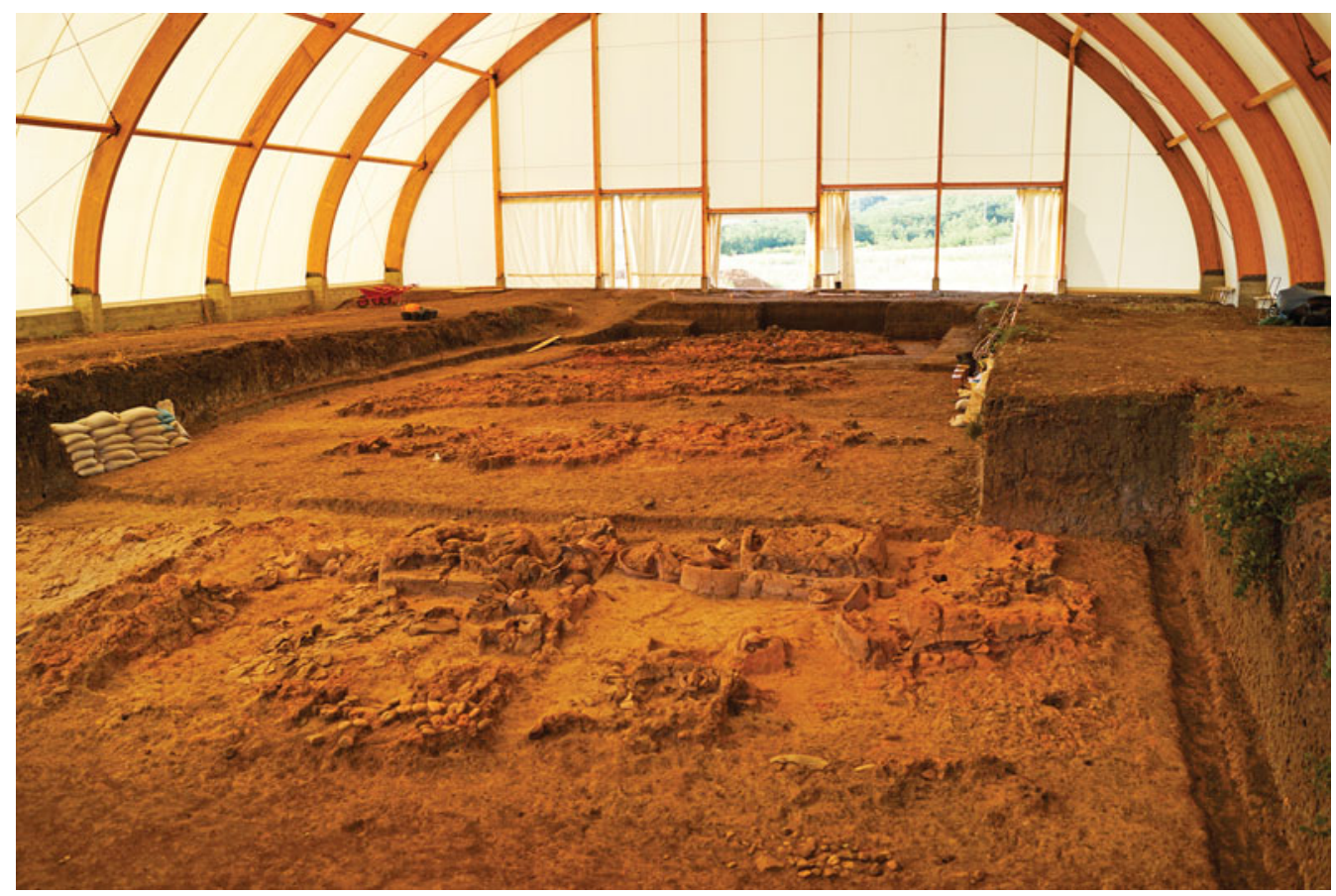

Figure 2. Remains of burnt houses.

\section{House excavations}

Excavations between 2012 and 2015 have focused on exploring the houses and the spaces between them (Figure 2). Five houses were investigated, four of which had been previously identified by the geomagnetic survey, and one which had not. One of the most important results was the identification of two-storey structures. It can confidently be claimed that three of the excavated houses had two storeys. The second floor of each of these houses took the form of a gallery, stretching across two-thirds of the floor-plan, with access via the western room. Figure 3 shows one of the collapsed galleries with associated fixed fittings and portable artefacts clearly visible.

House 1 in trench XIX is the best-preserved, presumably thanks to its thick cover of colluvium (Figures $4 \& 5$ ). It was a two-storey structure, $12 \times 5 \mathrm{~m}$; the ground floor featured three rooms separated by partition walls. The eastern and central rooms were of approximately the same dimensions, while the western room was smaller (Figure 5).

Two ovens were found in situ on the ground floor: one leaning against the northern wall of the eastern room and another on the northern wall of the central room (Figures 4 \& 5); there were no fixed features in the western room. Both ovens were horseshoe-shaped and had approximately the same dimensions. The oven in the eastern room had two adjoining clay receptacles: one of irregular circular shape was attached to its south-west corner, and the other, a narrow, shallow receptacle, was set along the oven's eastern side. On the western side of the oven, a grindstone lay inside a clay receptacle. In the north-east section of the house were the remains of a third oven that, evidently, had fallen from the gallery storey above.

(C) Antiquity Publications Ltd, 2017 


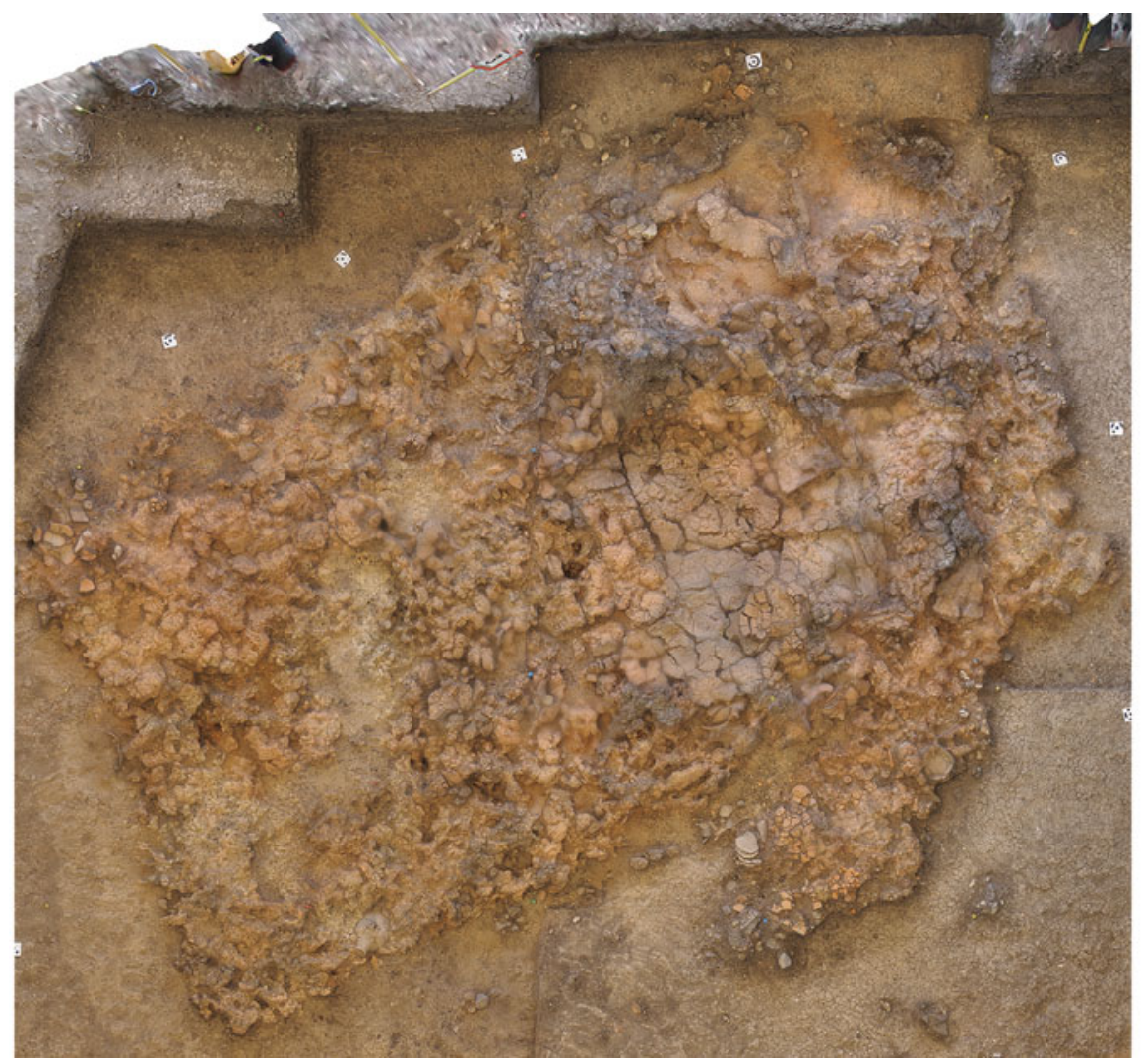

Figure 3. Burnt house with collapsed gallery.

The distribution of fixtures and finds provides a basis for the identification of discrete activity zones. With grindstones and many pottery vessels, the spaces around the ovens were undoubtedly used for food preparation; the clay container standing along the south wall of the eastern room, with stacked pottery vessels, could also have been connected with the food-preparation zone. Interestingly, the 'set' of food-related features-oven, vessels, grindstones-was repeated in multiple rooms, and may also have been present on the gallery-level above; in addition to the oven (above), the location of individual grindstones and pottery vessels suggests that some were derived from the upstairs gallery. These hypotheses will be tested through detailed stratigraphic analyses.

Space was clearly allocated for weaving in house 1 . There were two locations with clay objects, probably used as loomweights: the first along the western wall of the western room, and the second along the southern wall of the central room. A small clay table was found next to the weights in the central room (a similar situation was noted in a house at Divostin, Bogdanović 1988: 68). Another three tables were found in house 1, two of them next to the oven in the central room (Figure 6). As the weights in the central room did not lie on the floor surface, unlike the ones from the western room, we are inclined to think that both the weights and the table in the central room derived from the gallery

(C) Antiquity Publications Ltd, 2017 


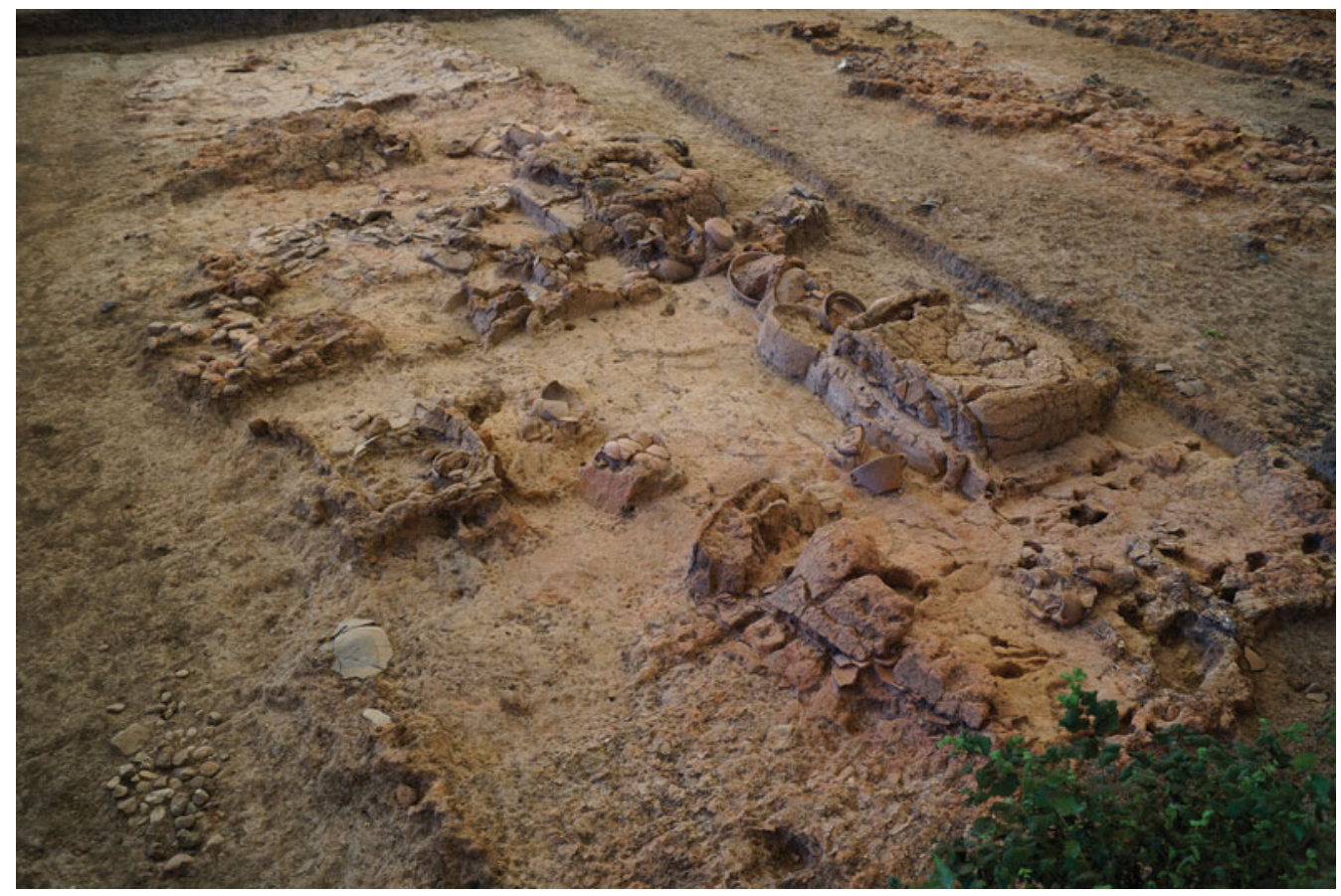

Figure 4. House in trench XIX with the remains of three ovens and clay container standing along the south wall of the eastern room.

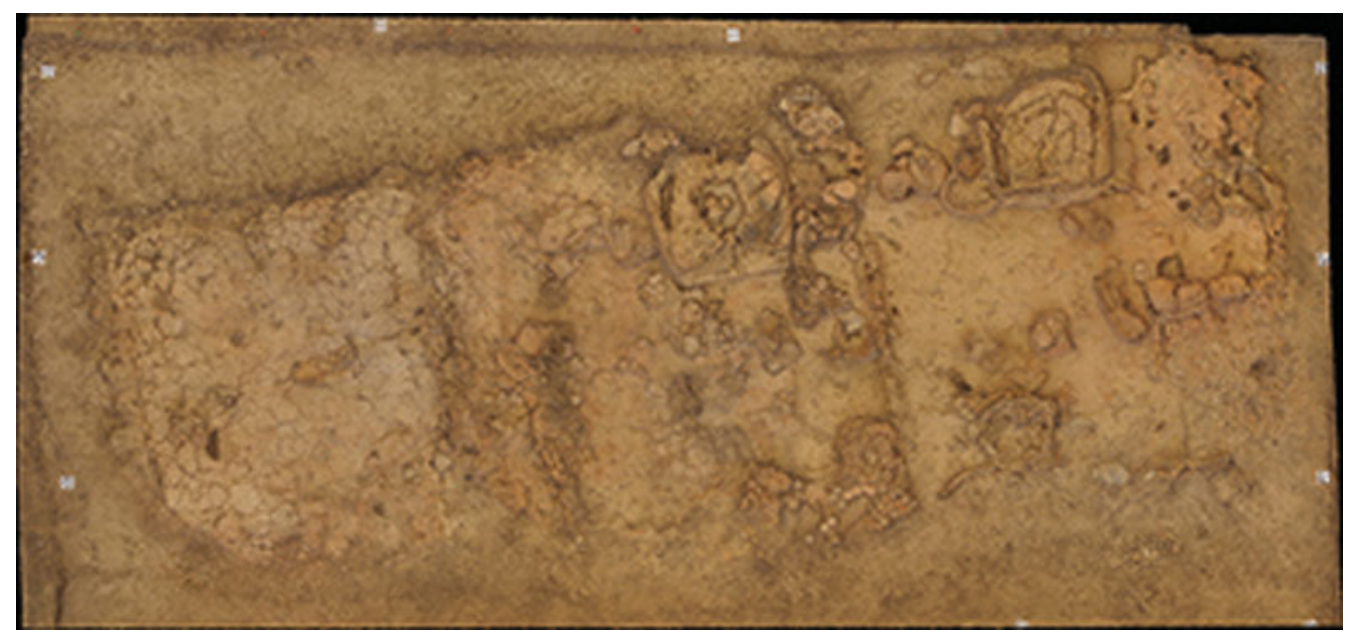

Figure 5. Orthophotograph of the house in trench XIX with visible partition walls and interior inventory.

during the collapse of the house. This preliminary analysis reveals that certain activities were repeated in separate rooms of the house. This may be significant for the interpretation of the division of activities inside the dwelling and the household's social organisation. The

(C) Antiquity Publications Ltd, 2017 


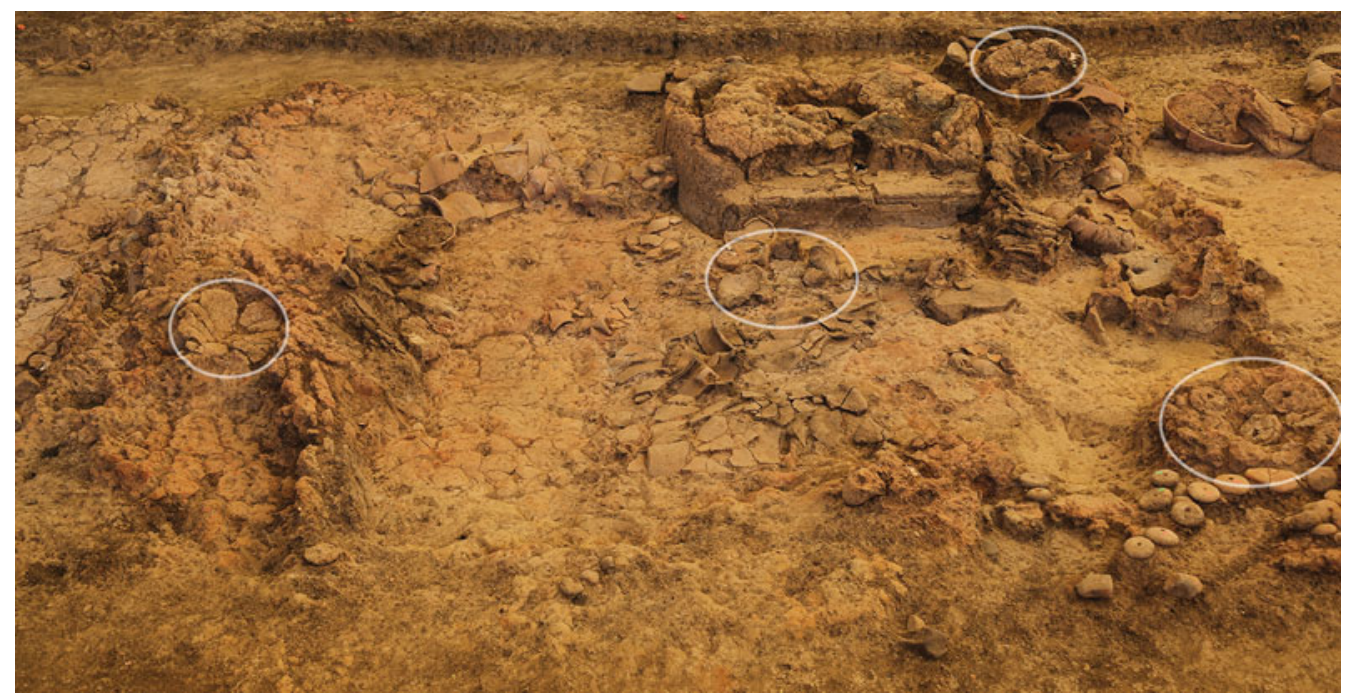

Figure 6. House in trench XIX—central room with marked clay tables.

fact that ovens appear in almost every room of the house-even the gallery-may indicate that two or three nuclear families shared the same house.

In the spaces outside the houses, no fixed structures, such as ovens or hearths (or, indeed, pits) were identified. Along the external southern wall of the house in trench XX, there was a considerable quantity of broken pottery, in addition to both worked and unworked stone and animal bone. No specific activity spaces, however, could be recognised. The spaces between houses bear no identifiable traces of burning, despite clear evidence that the houses themselves were destroyed by fire. Additionally, none of the structures investigated thus far has produced any evidence to suggest that the residents might have been injured or killed. Hence, the questions arise as to how and why these structures were burned and what happened to their residents. With these and many other questions still to resolve, it is nevertheless clear that Drenovac has enormous research potential concerning the many facets of the occupation and lifeways of a major Neolithic settlement.

\section{Acknowledgements}

This paper is a result of the project 'Archaeology of Serbia: cultural identity, factors of integration, technological processes and the role of the central Balkans in the development of European prehistory' (reference OI177020), funded by the Ministry of Education, Science and Technological Development of the Republic of Serbia.

\section{References}

Bogdanović, M. 1988. Architecture and structural features at Divostin, in A. McPherron \& D. Srejović (ed.) Divostin and the Neolithic of central Serbia: 35-141. Pittsburgh (PA): University of Pittsburgh, Department of Anthropology.
Perić, S. 2004. Problem of Neolithization in central Pomoravlje, in S. Perić (ed.) The central Pomoravlje in Neolithization of south east Europe. The Neolithic in the Middle Morava Valley (volume 1): 11-33. Belgrade: Institute of Archaeology, Belgrade Regional Museum Jagodina, Regional Museum Paraćin.

(C) Antiquity Publications Ltd, 2017 
- 2009. The oldest cultural horizon of trench XV at Drenovac. Starinar LVIII/2008: 29-41. Beograd.

Perić, S. \& O. Perić. 2014. Slatina-Turska Česma, Drenovac: arheološka istraživanja u 2013. Godini, Arheologija u Srbiji: projekti Arheološkog instituta u 2013. Godini: 12-16. Beograd: Arheološki institut.
Perić, S., C. Rummel, D. Peters, H. Wendling \& G. Schafferer. 2016. Geomagnetic survey of Neolithic settlements in the Middle Morava Valley-preliminary results, in S. Perić (ed.) The Neolithic in the Middle Morava Valley: new insights into settlements and economy (volume 2): 9-25. Belgrade: Institute of Archaeology, Belgrade, Regional Museum Paraćin

Vetnić, S. 1974. Počeci rada na ispitivanju kulture prvih zemljoradnika u srednjem Pomoravlju. Materijali SADJ X: 123-63. Beograd: Srpsko arheološko društvo, Gradski muzej Subotica. 